\title{
SKIM, a Candidate Satellite Mission Exploring Global Ocean Currents and Waves
}

\section{OPEN ACCESS}

Edited by:

Sabrina Speich,

École Normale Supérieure, France

Reviewed by:

Semyon Grodsky,

University of Maryland, College Park,

United States

John Wilkin,

Rutgers University, The State

University of New Jersey,

United States

Matthew Mazloff,

University of California, San Diego,

United States

*Correspondence:

Fabrice Ardhuin

ardhuin@ifremer.fr

Specialty section:

This article was submitted to

Ocean Observation,

a section of the journal

Frontiers in Marine Science

Received: 05 December 2018 Accepted: 03 April 2019

Published: 30 April 2019

Citation:

Ardhuin F, Brandt P, Gaultier L, Donlon

C, Battaglia A, Boy F, Casal T,

Chapron B, Collard F, Cravatte $S$,

Delouis J-M, De Witte E,

Dibarboure G, Engen G, Johnsen H,

Lique C, Lopez-Dekker P, Maes C, Martin A, Marié L, Menemenlis $D$,

Nouguier $F$, Peureux $C$, Rampal $P$,

Ressler G, Rio $\mathrm{M}-\mathrm{H}$, Rommen $\mathrm{B}$,

Shutler JD, Suess M, Tsamados M

Ubelmann $C$, van Sebille $E$, van den Oever $M$ and Stammer $D$ (2019) SKIM, a Candidate Satellite

Mission Exploring Global Ocean Currents and Waves.

Front. Mar. Sci. 6:209.

doi: 10.3389/fmars.2019.00209
Fabrice Ardhuin ${ }^{1 *}$, Peter Brandt ${ }^{2,3}$, Lucile Gaultier ${ }^{4}$, Craig Donlon ${ }^{5}$, Alessandro Battaglia ${ }^{6}$ François Boy ${ }^{7}$, Tania Casal ${ }^{5}$, Bertrand Chapron ${ }^{1}$, Fabrice Collard ${ }^{4}$, Sophie Cravatte ${ }^{8}$, Jean-Marc Delouis ${ }^{1}$, Erik De Witte ${ }^{5}$, Gerald Dibarboure ${ }^{7}$, Geir Engen ${ }^{9}$, Harald Johnsen ${ }^{9}$, Camille Lique ${ }^{1}$, Paco Lopez-Dekker ${ }^{10}$, Christophe Maes ${ }^{1}$, Adrien Martin ${ }^{11}$, Louis Marié ${ }^{1}$, Dimitris Menemenlis ${ }^{12}$, Frederic Nouguier ${ }^{1}$, Charles Peureux ${ }^{1}$, Pierre Rampal ${ }^{13}$, Gerhard Ressler ${ }^{5}$, Marie-Helene Rio ${ }^{14}$, Bjorn Rommen ${ }^{1}$, Jamie D. Shutler ${ }^{15}$, Martin Suess ${ }^{5}$, Michel Tsamados ${ }^{16}$, Clement Ubelmann ${ }^{17}$, Erik van Sebille ${ }^{18}$, Martin van den Oever ${ }^{6}$ and Detlef Stammer ${ }^{19}$

${ }^{1}$ Univ. Brest, CNRS, IRD, Ifremer, Laboratoire d'Océanographie Physique et Spatiale (LOPS), IUEM, Brest, France, ${ }^{2}$ GEOMAR Helmholtz-Zentrum für Ozeanforschung Kiel, Kiel, Germany, ${ }^{3}$ Kiel University, Kiel, Germany, ${ }^{4}$ OceanDataLab, Brest, France, ${ }^{5}$ European Space Agency, Noordwijk, Netherlands, ${ }^{6}$ National Centre for Earth Observation, University of Leicester, Leicester, United Kingdom, ${ }^{7}$ Centre National d'Etudes Spatiales, Toulouse, France, ${ }^{8}$ LEGOS, University of Toulouse, CNES, CNRS, IRD, UPS, Toulouse, France, ${ }^{9}$ Norut Information Technology Ltd., Tromsø, Norway, ${ }^{10}$ Geoscience and Remote Sensing Department, Delft University of Technology, Delft, Netherlands, ${ }^{11}$ National Oceanography Center, Southampton, United Kingdom, ${ }^{12}$ Jet Propulsion Laboratory, Pasadena, CA, United States, ${ }^{13}$ Nansen Environmental and Remote Sensing Center, Bergen, Norway, ${ }^{14}$ European Space Agency, Frascati, Italy, ${ }^{15}$ Center for Geography and Environmental Science, University of Exeter, Exeter, United Kingdom, ${ }^{16}$ Centre for Polar Observation and Modelling, Earth Sciences, University College London, London, United Kingdom, ${ }^{17}$ Collecte Localisation Satellites, Ramonville Saint Agne, France, ${ }^{18}$ Institute for Marine and Atmospheric Research, Utrecht University, Utrecht, Netherlands, ${ }^{19}$ Centrum für Erdsystemforschung und Nachhaltigkeit, Universität Hamburg, Hamburg, Germany

The Sea surface KInematics Multiscale monitoring (SKIM) satellite mission is designed to explore ocean surface current and waves. This includes tropical currents, notably the poorly known patterns of divergence and their impact on the ocean heat budget, and monitoring of the emerging Arctic up to $82.5^{\circ} \mathrm{N}$. SKIM will also make unprecedented direct measurements of strong currents, from boundary currents to the Antarctic circumpolar current, and their interaction with ocean waves with expected impacts on air-sea fluxes and extreme waves. For the first time, SKIM will directly measure the ocean surface current vector from space. The main instrument on SKIM is a Ka-band conically scanning, multi-beam Doppler radar altimeter/wave scatterometer that includes a state-of-the-art nadir beam comparable to the Poseidon-4 instrument on Sentinel 6 . The well proven Doppler pulse-pair technique will give a surface drift velocity representative of the top meter of the ocean, after subtracting a large wave-induced contribution. Horizontal velocity components will be obtained with an accuracy better than $7 \mathrm{~cm} / \mathrm{s}$ for horizontal wavelengths larger than $80 \mathrm{~km}$ and time resolutions larger than 15 days, with a mean revisit time of 4 days for of $99 \%$ of the global oceans. This will provide unique and innovative measurements that will further our understanding of the transports in the upper ocean layer, permanently distributing heat, carbon, plankton, and plastics. SKIM will also benefit from co-located measurements of water vapor, rain rate, sea ice concentration, and wind vectors provided by the European operational satellite 
MetOp-SG(B), allowing many joint analyses. SKIM is one of the two candidate satellite missions under development for ESA Earth Explorer 9. The other candidate is the Far infrared Radiation Understanding and Monitoring (FORUM). The final selection will be announced by September 2019, for a launch in the coming decade.

Keywords: ocean current, tropics, Arctic, Doppler, altimetry, sea state, remote sensing, ocean waves

\section{SCIENCE GAPS AND SKIM OBJECTIVES}

Satellite altimetry, combined with gravimetry and in situ drifter climatology, has provided a wealth of observations on surface currents during the past 25 years. Away from the Equator, the altimetry constellation resolves spatial scales larger than $200 \mathrm{~km}$ wavelength and time scales larger than 2 weeks (e.g., Ducet et al., 2000; Rio et al., 2014; Morrow et al., 2019). Large gaps remain in the observation capabilities of currents, winds and waves, especially in the Tropics, for extreme winds, and for frontal areas or small-scale processes that require highresolution measurements. These are particularly important at high latitudes. Development in the understanding of radar echoes from the oceans in Ka-band (Yurovsky et al., 2017), allowing higher resolution measurements, and of Doppler measurements in general (Chapron et al., 2005; Yurovsky et al., 2018) show that it is feasible to measure surface currents more directly. Responding to a fast-track call from the European Space Agency, SKIM leverages the development of near-nadir instruments such as SWIM (Hauser et al., 2017) with addition of Doppler processing. This combines a classical nadir altimeter with oblique beams, all operating in Ka-band. This instrument design offers a unique opportunity to explore ocean circulation beyond geostrophy and develop a new generation of global ocean circulation observing system, building on proven altimetry techniques. Other approaches, combining higher incidence angles scatterometry techniques with new antenna technology are also under development (Chelton et al., 2019).

Today's limited knowledge of currents is particularly problematic around the Equator, since it limits our capability to analyze and predict the mixed layer heat budget because the surface temperature variability is driven by ocean dynamics, with far-reaching impacts on the global climate (Hummels et al., 2014). Ocean assimilating models and reanalyses have little skill in reproducing equatorial surface currents, particularly meridional velocity fluctuations that peak at intraseasonal timescales (e.g., Schlundt et al., 2014), resulting in limited seasonal weather forecasting skills. Measuring surface currents with an accuracy of $0.1 \mathrm{~m} / \mathrm{s}$ on each component (zonal and meridional) for monthly averages at $300 \mathrm{~km}$ wavelengths and larger would provide a great step forward in our understanding of equatorial dynamics.

The high latitudes including ice-covered regions, and in particular the Arctic, are other regions with poor measurements of surface currents. These currents are important from a climate perspective as they transport freshwater from river run-off in the Arctic basin and melting of the Greenland ice sheet, to the North Atlantic where it can modify the intensity of deep water formation (e.g., Lique et al., 2016), impacting the global ocean circulation. Retrieving geostrophic currents from altimetry in icecovered regions is now possible (Armitage et al., 2017, 2018), albeit at too low resolution compared to the dominant energycontaining structures, with horizontal scales characterized by the Rossby deformation radius, typically smaller than $10 \mathrm{~km}$ in these regions. Both small-scale eddies and wind-driven currents must be resolved in the ice-covered regions to better quantify and understand the cross-shelf fluxes of heat and freshwater (e.g., Spall et al., 2018; Stewart et al., 2018), the location and evolution of the polar and subpolar gyres (Armitage et al., 2017, 2018; Dotto et al., 2018), as well as the regions of deep water convection (e.g., Lique and Thomas, 2018).

Figures 1D-F illustrates the intense circulation patterns across the ice edge that are expected from numerical modeling but only known qualitatively because quantitative analysis methods using optical or SAR image pairs fail due to its rapid dynamics. The Arctic marginal ice zone is a "mare incognitum" that, by the year 2030, is predicted to expand significantly, under the combined effect of atmospheric and oceanic warming, enhanced ice fragmentation by waves (Aksenov et al., 2017) and increased influence of ocean mesoscale activity (Manucharyan and Thompson, 2017). Measurements are missing to address the questions on freshwater transport and ice edge evolution. SKIM will be the first mission to provide much needed data on surface currents, ice drift and wave spectra (e.g., Stopa et al., 2018), at higher spatio-temporal resolution than is available today. These observations are needed to improve the parameterizations of turbulent fluxes, sea ice rheology, wave-ice interactions, and ocean circulation in climate models and weather forecasting systems.

Resolving waves down to $30 \mathrm{~m}$ wavelength, SKIM measurements will provide accurate estimates of the Stokes drift profile in oceans, marginal, and inland seas. Combined with the surface current measurement, Stokes drift data will lead to more accurate analysis and simulation of the poorly known pathways of floating material such as (plastic) debris, abandoned fishing gear, and biological material (Maes et al., 2018; van Sebille et al., 2018). For example, Fraser et al. (2018) showed that kelp found on Antarctic coastlines could only have traveled from lower-latitude sites where it normally grows, thanks to the southward Stokes drift that opposes the northward Ekman transport. As Lagrangian pathways are typically very sensitive to the flow field, accurate knowledge of the surface flow improves our ability to track surface floating debris and determine how microplastic at the surface ocean is transported from coastlines into the open-ocean accumulation zones (Lebreton et al., 2018). 


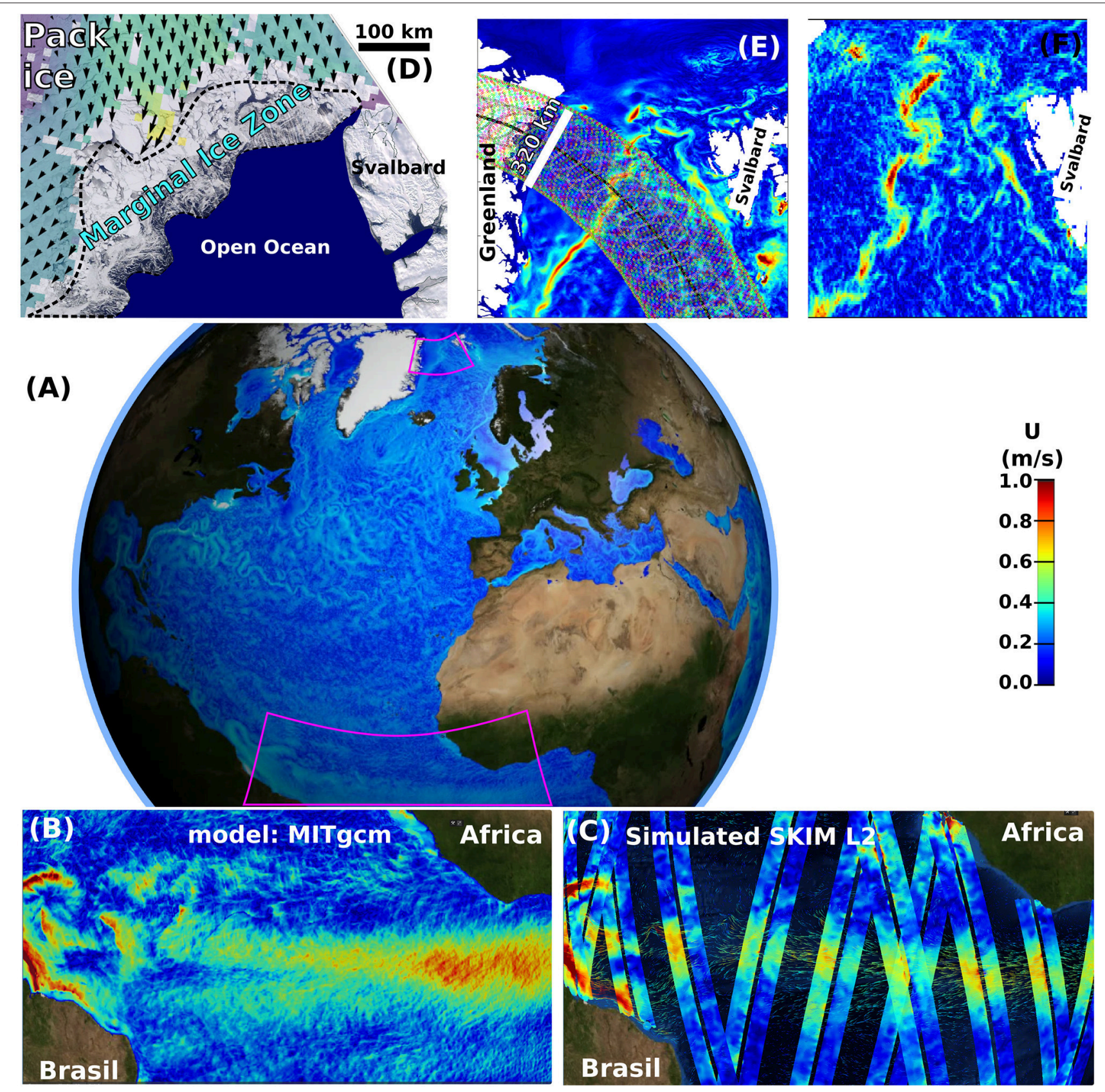

FIGURE 1 | (A) Example snapshot of the global ocean current magnitude (color) as given by the MITgcm 1/48 global model simulation LLC4320 (Rocha et al. 2016), containing density-driven, wind-driven, and tidal currents. The pink boxes around Fram strait and the tropical Atlantic correspond to the other panels. The color bar corresponds to (B,C,E,F). (B) close-up on the Tropical Atlantic, and (C) a 1-day coverage by SKIM including realistic measurement uncertainties. The central part of the swaths is masked where uncertainties on the along-track velocity component are largest. (D) Example of marginal ice zone in Fram strait viewed with optical imagery and characterized by ice bands along the meandering ice edge, with large floes in the ice pack. Ice drift (colors and arrows) is estimated over the ice pack from Sentinel-1 image pair correlations, courtesy of A. Korosov (NERSC). (E) Modeled ocean circulation at high resolution (Hutter et al., 2018) showing intense ice-edge jets and Svalbard coastal current that would be observed several times a day by SKIM. The footprints of SKIM across a $320-\mathrm{km}$ swath are represented by small colored circles. (F) Multi-swath surface current magnitude including realistic measurement uncertainties. This figure is adapted from The SKIM Team (2017).

The combination of surface currents and wave measurements are also needed to better understand high sea states (Ardhuin et al., 2017; Quilfen et al., 2018) and extreme individual waves (Fedele et al., 2016). As currents define the spatial patterns of sea states at scales under $200 \mathrm{~km}$, they also impact and coastal hazards in a way that is poorly known, contributing to large uncertainties in extreme coastal sea levels (e.g., Guza and Feddersen, 2012; Dodet et al., 2018). 
The ocean uptake of greenhouse gases is highly variable in space and time, and has so far been responsible for the absorption of about $25 \%$ of the total anthropogenic $\mathrm{CO}_{2}$ (Le Quéré et al., 2016). This flux is strongly influenced by horizontal transport across high gradient regions. Among these, continental shelves, covering just $\sim 5 \%$ of the world ocean's surface, play an important role in the global carbon. The heterogeneous nature of shelves (e.g., Canals et al., 2006; Bröder et al., 2018), and the difficulty to obtain reliable current estimates there, means that carbon dynamics are often poorly quantified and monitored within these regions. Accurate knowledge of surface water velocities across continental shelf boundaries, vertical shear and turbulence, and surface divergence will improve our ability to monitor how the oceans are impacted and reacting to a changing climate.

We need better measurements of surface currents and waves for all the scientific and societal questions listed above, and many other applications (The SKIM Team, 2017). This is critical to better understand the ocean's role in the Earth system. With SKIM, kinematic variables (surface current, ice drift, waves) can be resolved at smaller scales than those at which dynamic variables (sea level, wind stress) are available today, and complementary to planned higher resolution missions such as SWOT for sea level (Morrow et al., 2019), and CIMR for surface temperature and salinity (Kilic et al., 2018).

\section{SKIM MEASUREMENT PRINCIPLE}

The SKIM mission concept, now being studied, is designed to fly in tandem with the operational satellite MetOp-SG(B), following a sun-synchronous orbit at an altitude of $824 \mathrm{~km}$. The main innovation is the combination of rotating beams similar to SWIM on CFOSAT, here with incidence angles $\theta_{i}=0$ (nadir), 6 and $12^{\circ}$, with a Doppler capability that will measure the surface velocity vector and ocean wave spectra across a $320-\mathrm{km}$ swath.

The sampling properties of SKIM are summarized and illustrated in Figure 2.

Starting with the lowest level data in Figure 2A, SKIM measures backscattered power and Doppler velocity in rangeresolved beams with $0.7-\mathrm{m}$ line of sight resolution. For $12^{\circ}$ incidence, this gives a ground-projected resolution of $3.5 \mathrm{~m}$. The velocity is given by the phase different of consecutive pulses (pulse-pairs) transmitted at a frequency of $32 \mathrm{KHz}$. This high pulse repetition frequency guarantees a high coherence between consecutive pulses. These range-resolved data correspond to averages in the azimuth direction, so that all patterns are averaged out except for features, including modulating waves, perpendicular to the range direction. This is the principle of the "matching wavefront technique" demonstrated with airborne radars (Jackson et al., 1985), and now working in space with the Ku-band SWIM radar on CFOSAT. SWIM uses much larger $(18 \mathrm{~km})$ footprints than SKIM, and SKIM includes a Doppler processing that is not available on SWIM. SAR-unfocused processing is used on SKIM to improve azimuthal resolution, down to $300 \mathrm{~m}$, and enhance the modulation signals (see Nouguier et al., 2018). This resolution in range and azimuth will be also used to remove outliers within the radar footprint, such as the ship that appears as a white spot in Figure 2C, and to correct for Doppler biases due to variations of backscatter power with azimuth. Each footprint produces measurements of the current velocity along the local range direction, and a wavenumber spectrum of waves propagating to and from the range direction, similar to the SWIM instrument on CFOSAT (Hauser et al., 2017), but resolving shorter wave components, down to $30 \mathrm{~m}$ wavelength compared to $70 \mathrm{~m}$ with SWIM. These footprints are arranged in the pattern shown in Figure 2D.

The combination of all beams across the $320 \mathrm{~km}$ wide swath shown in Figure 2D is such that each $30 \times 30 \mathrm{~km}$ square contains at least two measurements, giving the two components of the current vector. The full directional wave spectrum is obtained over a $75 \times 75 \mathrm{~km}$ box. As discussed by Rodríguez et al. (2018) for the DopplerScat airborne instrument, this viewing geometry suffers from a Geometrical Dilution of Precision, well known for coastal HF radar instruments. Namely, the outer part of the swath mostly contains measurements of the cross-track velocity component while at nadir only the alongtrack velocity is measured. This, however, can be mitigated using a cross-track estimate of the geostrophic part of the current using the sea surface height anomaly given by the nadir beam.

The most novel measurement of SKIM is the line of sight velocity $V_{\text {LOS }}$ using off-nadir beams. Given the incidence $\theta_{i}$, the ground projection into a radial component $V_{\text {LOS }} / \sin \theta_{i}$ that contains a non-geophysical contribution $V_{\mathrm{NG}} / \sin \theta_{i}$ due to the satellite velocity (around $7 \mathrm{~km} / \mathrm{s}$ ), and Earth rotation (around $400 \mathrm{~m} / \mathrm{s}$ ). The residual, a few meters per second, is the geophysical velocity. In the case of the baseline pulse-pair processing, it contains a wave contribution to the Doppler $U_{\mathrm{WD}}$ of the order of $1.5 \mathrm{~m} / \mathrm{s}$ similar to the one measured with Envisat (Figure 5 in Chapron et al., 2005), and the surface current, of the order of $0.3 \mathrm{~m} / \mathrm{s}$, averaged over the top meter. An experimental delta-K processing with three fixed delta-K bands will also be implemented. This is similar to HF radar with a well-known $U_{\mathrm{WD}}$ equal to the phase speed associated to the selected wavelength and a current averaged over different depth ranges, typically the top 5, 12, and $20 \mathrm{~m}$. Therefore, SKIM will give complementary estimates, from pulse-pair and delta-K processing, of the near-surface current from the $V_{\text {LOS }}$ integrated over different depths,

$$
U=\left(V_{\mathrm{LOS}}-V_{\mathrm{NG}}\right) / \sin \theta_{i}-U_{\mathrm{WD}}=U_{\mathrm{GD}}-U_{\mathrm{WD}} .
$$

The accuracy of SKIM current retrieval relies on excellent pointing retrieval and the combination of wind vector, from MetOp-SG(B), and wave parameters from both the nadir and oblique beams, in order to estimate $U_{\mathrm{WD}}$ within a few percent.

The contemporaneous measurements of ice and rain detection from the MWI radiometer on MetOp-SG(B) will provide additional flag-setting capabilities that are otherwise based on the variance of backscatter and Doppler within each SKIM footprint. Also, MWI water vapor will be used in the wet tropospheric range correction for the nadir beam. More importantly, the contemporaneous measurement of wind vectors from SCA on MetOp-SG, with currents and waves from SKIM, opens 


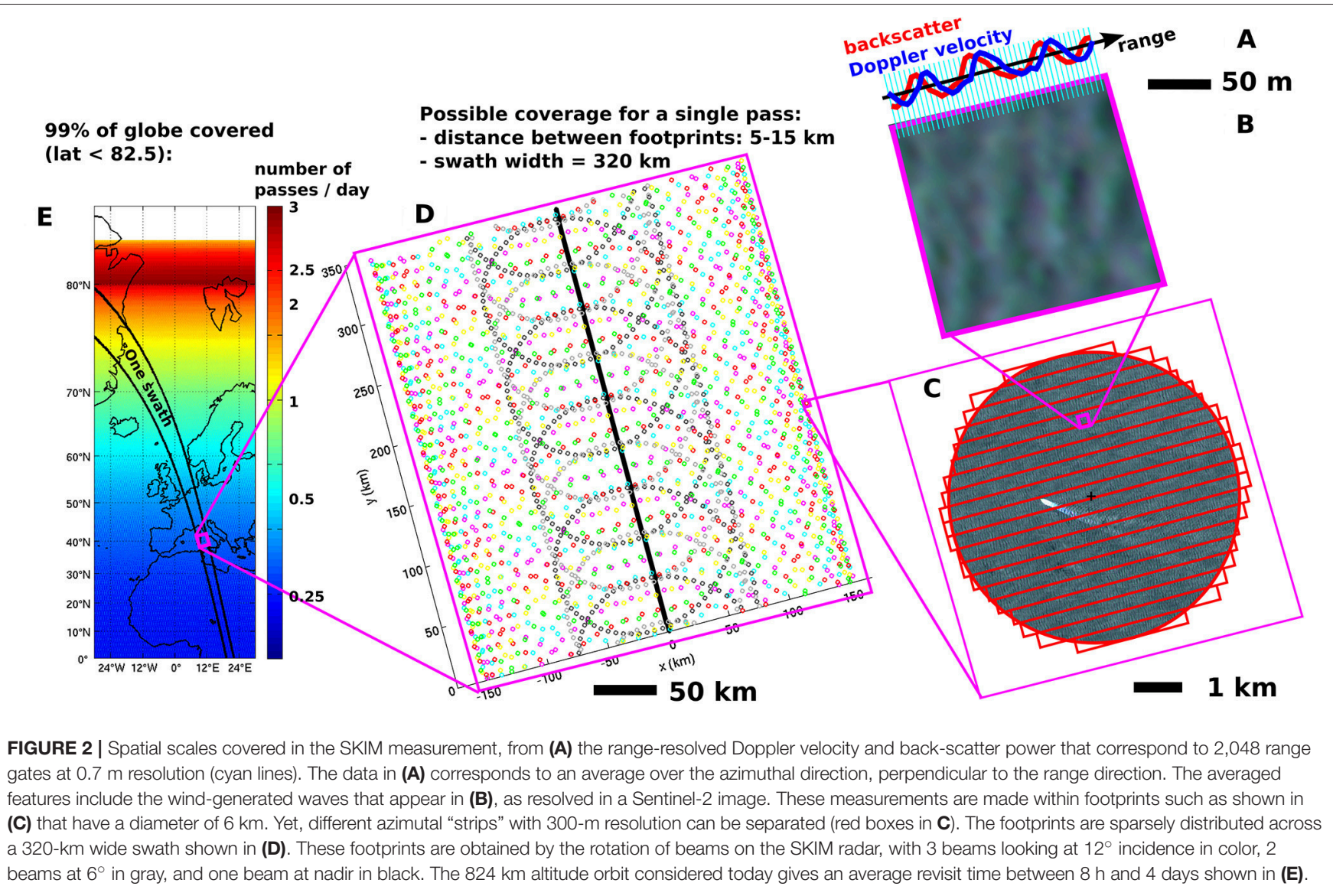

possibilities for a wide range of applications. Just like the full wave spectrum measurement will lead to a revisit in the analysis of wave-induced biases in nadir altimetry, this first measurement of full wave spectra and scatterometer winds will also be unique for estimating and correcting systematic currents (Quilfen et al., 2004) and sea state biases in wind retrievals. The combination of the two missions is also a distinctive opportunity to refine our understanding of air-sea energy (wind work) and momentum (wind stress) fluxes.

SKIM provides a higher spatial resolution than today's altimeter constellation, comparable to the resolution of SWOT, thanks to a wider swath. Because smaller scales move faster, this new data will bring particular challenges related to the aliasing of near-inertial currents, semi-diurnal internal tides, and diurnal cycles of currents that are important in the tropics. This may call for a separation of unbalanced (wind-driven, near-inertial, internal tides) and balanced (i.e., geostrophic) motions that is a very active topic of research, in particular in the context of the SWOT mission (e.g., Torres et al., 2018; Morrow et al., 2019). Although the average time revisit of SKIM (4 days) is large, part of the fast motions are coherent over 4 inertial periods and relatively large horizontal scales (e.g., Kim and Kosro, 2013). Ongoing work suggests that inertial oscillations in the SKIM data may be separated from the more slowly-evolving motions. These efforts are complementary to those focused on the sea surface expression of internal waves in the context of SWOT (Morrow et al., 2019). Finally, with a launch date in the coming decade and a design lifetime of 5 years, SKIM may fly for some time together with SWOT, with highly complementary measurements for the joint analysis of balanced and unbalanced motions, and their interactions.

\section{EXPECTED PERFORMANCE}

The main requirement for surface velocity measurement for SKIM is related to the scientific applications described above with a root mean square accuracy of $0.07 \mathrm{~m} / \mathrm{s}$ for each velocity component, zonal and meridional, for wavelengths larger than $100 \mathrm{~km}$, and time scales over 15 days. The spatial scales are relaxed to $200 \mathrm{~km}$ for tropical latitudes. The performance of SKIM is thus tested by verifying that simulated SKIM measurements, based on modeled currents and waves, are consistent with the input model fields. The modeled currents used here, from the MITgcm, probably overestimate the internal wave energy by about a factor 2 , and underestimate the nearinertial energy by about a factor 2 (Menemenlis, personal communication). These biases are not yet corrected for when the SKIM performance is evaluated, and we expect that the effective SKIM resolution found here may be slightly optimistic away from the tropics due to the underestimated near-inertial energy.

At present, the main source of uncertainty in our retrieval of the surface current is due to the uncertainty on $U_{\mathrm{WD}}$. At Ka-band 
and for incidences less than $20^{\circ}, U_{\mathrm{WD}}$ is of the order of 25 times the radial component of the surface Stokes drift $U_{S}$ (Nouguier et al., 2018; Yurovsky et al., 2018), and $U_{S}$ is approximately $1.2 \%$ of the radial wind component (Rascle et al., 2006); (Peureux et al., 2018).

Accurate measurements of the geophysical surface velocity $U_{\mathrm{GD}}$ require a very accurate knowledge of the platform attitude, and characterization of the backscatter inhomogeneities within the footprint, which can be due to rain, wind variability, slicks, ships, etc. For the rotating SKIM configuration, the pitch and roll of the radar beam can be estimated from the variation in back scatter cross-section across the footprint (Ardhuin et al., 2018). More crucial is the mis-knowledge the yaw pointing. A yaw error of $0.001^{\circ}$ causes a Doppler shift of $30 \mathrm{~Hz}$ amplitude for $\theta_{i}=12^{\circ}$, and is equivalent to a mean cross-track current error of $\approx 10 \mathrm{~cm} / \mathrm{s}$. The requirements on the yaw knowledge for the SKIM radar has thus been refined to take advantage of the rotating beam geometry using a data-driven approach similar to Rodríguez et al. (2018), with a residual attitude-related uncertainty on the retrieved current of a few centimeter per second, accomodated within the mission requirements.

The separation of wave $U_{\mathrm{WD}}$ and current $U$ contributions to the Doppler velocity is complicated by the natural correlation of waves and currents at the scales of interest (Ardhuin et al., 2017). Previous Doppler current measurements (Rouault et al., 2010; Martin et al., 2016) used a wind-derived proxy to correct for the wave bias. However, for any given location, $U_{\mathrm{WD}}$ has root mean square variations of $\pm 40 \%$ for any wind speed, due to the variability in the sea state (Ardhuin et al., 2018). Adding sea state parameters from the resolved modulations and the near-nadir measurements of wave height and mean square slope lead to an uncertainty on $U_{\mathrm{WD}}$ that is under $10 \%$, accounting for $30-50 \%$ of the overall uncertainty on the surface current retrieval, depending on the strength of surface current gradients and on the local wave field (Ardhuin et al., 2018). We have thus investigated different regions of interest to estimate SKIM uncertainties. Looking at the along-track coherence of the crosstrack current between the simulated SKIM currents and the input surface current fields, we define the effective resolution as the wavelength at which the coherence drops below 0.5 .

Starting from single footprints, $6 \mathrm{~km}$ in diameter, the root mean square uncertainties for the radial current component are around $0.1 \mathrm{~cm} / \mathrm{s}$. For gridded current components, uncertainties are reduced by spatial averaging. Our current approach uses optimal interpolation leading to an effective resolution that is within the requirements, typically around $70 \mathrm{~km}$ wavelength when considering a single swath corresponding to a snapshot of the surface current. When considering the time evolution of the surface current and comparing that to a multi-swath SKIM simulated product, the smaller scales are not resolved because they move faster, and the effective resolution ranges from $70 \mathrm{~km}$ at high latitude, to $250 \mathrm{~km}$ at the equator, as illustrated in Figure 1. We typically find $80 \mathrm{~km}$ at mid latitude which is half of the effective resolution of today's nadir satellite altimeter constellation.

Future work will certainly better take wave-current correlations into account. A direct assimlation of the total geophysical velocity in a coupled wave-current models should be an optimal use of the data, fully taking advantage of the combined wave and current measurements.

\section{CONCLUSIONS}

SKIM builds on the proven altimetry technique for sea surface height and derived geostrophic near-surface current estimates, adding a global monitoring of all ageostrophic flow components. SKIM will for the first time measure the full surface current vector at the same time as highly resolved twodimensional and unambiguous wave spectra over the global ocean. This will reveal the transport of heat in the tropics, freshwater in the Arctic and plankton or plastics everywhere with unprecedented resolution. SKIM will also resolve the sea states in all marginal and enclosed seas. By flying in formation with MetOp-SG(B), SKIM will allow unique analyses of air-sea fluxes that will use wind vector measurements, rain rate, and sea ice concentration.

All this will happen if the SKIM concept is indeed selected to become the 9th ESA Earth Explorer mission, a selection that will happen in Summer 2019 based on the result of simulations and campaign analysis, that will benefit from the mobilization of the oceanographic community and demonstrate the soundness of the SKIM concept. We hope to celebrate this success at the upcoming OceanObs'19 conference, and we will work with the community to define a roadmap on the development of tools and validation plans. These are needed to facilitate the uptake, over the next decade, of the new globally measured variable that is the total surface current vector.

\section{AUTHOR CONTRIBUTIONS}

DM and FA provided the numerical model output that was analyzed for SKIM performance by LG and CU. J-MD, FC, and $\mathrm{CU}$ performed the analysis of attitude effects and data-driven attitude corrections. PB, FA, SC, CD, DM, JS, MT, and EvS wrote the science objectives. All authors contributed to the final editing of the manuscript.

\section{FUNDING}

Part of this work was supported by the European Space Agency (ESA) through the Sea surface KInematics Multiscale monitoring (SKIM) Mission Science (SciSoc) Study (Contract 4000124734/18/NL/CT/gp), SKIM-MPRC (4000124664/18/NL/NA), and SKIM-PE (4000124521/18/NL/CT. Additional support was provided by CNES and ANR grants for ISblue (ANR-17-EURE-0015) LabexMER (ANR-10-LABX-19).

\section{ACKNOWLEDGMENTS}

Discussions with and comments from L. L. Fu, S. Bacon, A. Naveira-Garabato and E. Frajka-Williams are gratefully acknowledged. 


\section{REFERENCES}

Aksenov, Y., Popova, E. E., Yool, A., Nurser, A. G., Williams, T. D., Bertino, L., et al. (2017). On the future navigability of arctic sea routes: highresolution projections of the arctic ocean and sea ice. Mar. Policy 75, 300-317. doi: 10.1016/j.marpol.2015.12.027

Ardhuin, F., Aksenov, Y., Benetazzo, A., Bertino, L., Brandt, P., Caubet, E., et al. (2018). Measuring currents, ice drift, and waves from space: the sea surface kinematics multiscale monitoring (SKIM) concept. Ocean Sci. 14, 337-354. doi: 10.5194/os-14-337-2018

Ardhuin, F., Rascle, N., Chapron, B., Gula, J., Molemaker, J., Gille, S. T., et al. (2017). Small scale currents have large effects on wind wave heights. J. Geophys. Res. 122, 4500-4517. doi: 10.1002/2016JC012413

Armitage, T. W., Kwok, R., Thompson, A. F., and Cunningham, G. (2018). Dynamic topography and sea level anomalies of the southern ocean: variability and teleconnections. J. Geophys. Res. 123, 613-630. doi: 10.1002/2017JC0 13534

Armitage, T. W. K., Bacon, S., Ridout, A. L., Petty, A. A., Wolbach, S., and Tsamados, M. (2017). Arctic ocean surface geostrophic circulation 2003-2014. Cryosphere 11, 1767-1780. doi: 10.5194/tc-11-1767-2017

Bröder, L., Tesi, T., Andersson, A., Semiletov, I., and Gustafsson, Ö. (2018). Bounding cross-shelf transport time and degradation in Siberian-Arctic landocean carbon transfer. Nuovo Cimento 8:806. doi: 10.1038/s41467-018-03192-1

Canals, M., Puig, P., de Madron, X. D., Heussner, S., Palanques, A., and Fabres, J. (2006). Flushing submarine canyons. Nature 444, 354-357. doi: 10.1038/nature05271

Chapron, B., Collard, F., and Ardhuin, F. (2005). Direct measurements of ocean surface velocity from space: interpretation and validation. J. Geophys. Res. 110:C07008. doi: 10.1029/2004JC002809

Chelton, D. B., Schlax, M. G., Samelson, R. M., Farrar, J. T., Molemaker, M. J., and Gula, J. C. M. J. (2019). Prospects for future satellite estimation of smallscale variability of ocean surface velocity and vorticity. Progr. Oceanogr. 173, 256-350. doi: 10.1016/j.pocean.2018.10.012

Dodet, G., Leckler, F., Sous, D., Ardhuin, F., Filipot, J., and Suanez, S. (2018). Wave runup over steep rocky cliffs. J. Geophys. Res. 123, 7185-7205. doi: 10.1029/2018JC013967

Dotto, T. S., Naveira Garabato, A., Bacon, S., Tsamados, M., Holland, P. R., Hooley, J., et al. (2018). Variability of the ross gyre, southern ocean: drivers and responses revealed by satellite altimetry. Geophys. Res. Lett. 45, 6195-6204. doi: 10.1029/2018GL078607

Ducet, N., Traon, P. Y. L., and Reverdin, G. (2000). Global high-resolution mapping of ocean circulation from TOPEX/Poseidon and ERS-1 and -2. J. Geophys. Res. 105, 19477-19498. doi: 10.1029/2000JC900063

Fedele, F., Brennan, J., de León, S. P., Dudley, J., and Dias, F. (2016). Real world ocean rogue waves explained without the modulational instability. Sci. Rep. 6:27715. doi: 10.1038/srep27715

Fraser, C. I., Morrison, A. K., Hogg, A. M., Macaya, E. C., van Sebille, E., Ryan, P. G., et al. (2018). Antarctica's ecological isolation will be broken by storm-driven dispersal and warming. Nat. Clim. Change 8, 704-708. doi: 10.1038/s41558-018-0209-7

Guza, R. T., and Feddersen, F. (2012). Effect of wave frequency and directional spread on shoreline runup. Geophys. Res. Lett. 39:L11607. doi: 10.1029/2012GL051959

Hauser, D., Tison, C., Amiot, T., Delaye, L., Corcoral, N., and Castillan, P. (2017). SWIM: the first spaceborne wave scatterometer. IEEE Trans. Geosci. Rem. Sens. 55, 3000-3014. doi: 10.1109/TGRS.2017.2658672

Hummels, R., Dengler, M., Brandt, P., and Schlundt, M. (2014). Diapycnal heat flux and mixed layer heat budget within the atlantic cold tongue. Coast. Dyn. 43, 3179-3199. doi: 10.1007/s00382-014-2339-6

Hutter, N., Losch, M., and Menemenlis, D. (2018). Scaling properties of arctic sea ice deformation in a high-resolution viscous-plastic sea ice model and in satellite observations. J. Geophys. Res. 123, 672-687. doi: 10.1002/2017JC013119

Jackson, F. C., Walton, W. T., and Peng, C. Y. (1985). A comparison of in situ and airborne radar observations of ocean wave directionality. J. Geophys. Res. 90, 1005-1018. doi: 10.1029/JC090iC01p01005

Kilic, L., Prigent, C., Aires, F., Boutin, J., Heygster, G., Tonboe, R. T., et al. (2018). Expected performances of the copernicus imaging microwave radiometer (cimr) for an all-weather and high spatial resolution estimation of ocean and sea ice parameters. J. Geophys. Res. 123, 7564-7580. doi: 10.1029/2018JC014408

Kim, S. Y., and Kosro, P. M. (2013). Observations of near-inertial surface currents off Oregon: decorrelation time and length scales. J. Geophys. Res. 118, 37233736. doi: 10.1002 /jgrc. 20235

Le Quéré, C., Andrew, R. M., Canadell, J. G., Sitch, S., Korsbakken, J. I., Peters, G. P., et al. (2016). Global carbon budget 2016. Earth Syst. Sci. Data 8, 605-649. doi: 10.5194/essd-8-605-2016

Lebreton, L. C. M., Slat, B., Ferrari, F., Sainte-Rose, B., Aitken, J., Marthouse, R., et al. (2018). Evidence that the Great Pacific Garbage Patch is rapidly accumulating plastic. Sci. Rep. 8:4666. doi: 10.1038/s41598-018-22939-w

Lique, C., Holland, M. M., Dibike, Y. B., Lawrence, D. M., and Screen, J. A. (2016). Modeling the arctic freshwater system and its integration in the global system: lessons learned and future challenges. J. Geophys. Res. 121, 540-566. doi: 10.1002/2015JG003120

Lique, C., and Thomas, M. D. (2018). Latitudinal shift of the atlantic meridional overturning circulation source regions under a warming climate. Nat. Clim. Change 8:1013. doi: 10.1038/s41558-018-0316-5

Maes, C., Grima, N., Blanke, B., Martinez, E., Paviet-Salomon, T., and Huck, T. (2018). A surface 'super-convergence' pathway connecting the South Indian Ocean to the subtropical South Pacific gyre. Geophys. Res. Lett. 121, 49-75. doi: 10.1002/2017GL076366

Manucharyan, G. E., and Thompson, A. F. (2017). Submesoscale sea iceocean interactions in marginal ice zones. J. Geophys. Res. 122, 9455-9475. doi: 10.1002/2017JC012895

Martin, A. C. H., Gommenginger, C., Marquez, J., Doody, S., Navarro, V., and Buck, C. (2016). Wind-wave-induced velocity in ati sar ocean surface currents: first experimental evidence from an airborne campaign. J. Geophys. Res. 121, 1640-1653. doi: 10.1002/2015JC011459

Morrow, R., Fu, L.-L., Ardhuin, F., Benkiran, M., Chapron, B., Cosme, E., et al. (2019). Global observations of fine-scale ocean surface topography with the Surface Water and Ocean Topography (SWOT) mission. Front. Mar. Sci. 6:00232. doi: 10.3389/fmars.2019.00232

Nouguier, F., Chapron, B., Collard, F., Mouche, A., Rascle, N., Ardhuin, F., et al. (2018). Sea surface kinematics from near-nadir radar measurements. IEEE Trans. Geosci. Remote Sens. 56, 6169-6179. doi: 10.1109/TGRS.2018.2833200

Peureux, C., Benetazzo, A., and Ardhuin, F. (2018). Note on the directional properties of meter-scale gravity waves. Ocean Sci. 14, 41-52. doi: 10.5194/os-14-41-2018

Quilfen, Y., Chapron, B., and Vandemark, D. (2004). The ERS scatterometer wind measurement accuracy: evidence of seasonal and regional biases. J. Atmos. Ocean Technol. 18, 1684-1697. doi: 10.1175/1520-0426(2001)018<;1684:TESWMA $>; 2.0 . C O ; 2$

Quilfen, Y., Yurovskaya, M., Chapron, B., and Ardhuin, F. (2018). Storm waves sharpening in the Agulhas current: satellite observations and modeling. Remote Sens. Environ. 216, 561-571. doi: 10.1016/j.rse.2018.07.020

Rascle, N., Ardhuin, F., and Terray, E. A. (2006). Drift and mixing under the ocean surface. A coherent one-dimensional description with application to unstratified conditions. J. Geophys. Res. 111:C03016. doi: 10.1029/2005JC003004

Rio, M.-H., Mulet, S., and Picot, N. (2014). Beyond GOCE for the ocean circulation estimate: synergetic use of altimetry, gravimetry, and in situ data provides new insight into geostrophic and Ekman currents. Geophys. Res. Lett. 41, 8918-8925. doi: 10.1002/2014GL061773

Rocha, C. B., Chereskin, T. K., and Gille, S. T. (2016). Mesoscale to submesoscale wavenumber spectra in Drake passage. J. Phys. Oceanogr. 46, 601-620. doi: 10.1175/JPO-D-15-0087.1

Rodríguez, E., Wineteer, A., Perkovic-Martin, D., Gál, T., Stiles, B. W., Niamsuwan, N., et al. (2018). Estimating ocean vector winds and currents using a Ka-band pencil-beam doppler scatterometer. Remote Sens. 4:576. doi: $10.3390 /$ rs 10040576

Rouault, M. J., Mouche, A., Collard, F., Johannessen, J. A., and Chapron, B. (2010). Mapping the agulhas current from space: an assessment of ASAR surface current velocities. J. Geophys. Res. 115:C10026. doi: 10.1029/2009JC006050

Schlundt, M., Brandt, P., Dengler, M., Hummels, R., Fischer, T., Bumke, K., et al. (2014). Mixed layer heat and salinity budgets during the onset of the 2011 Atlantic cold tongue. J. Geophys. Res. 119, 7882-7910. doi: 10.1002/2014JC010021 
Spall, M. A., Pickart, R. S., Li, M., Itoh, M., Lin, P., Kikuchi, T., et al. (2018). Transport of pacific water into the canada basin and the formation of the chukchi slope current. J. Geophys. Res. 123, 7453-7471. doi: 10.1029/2018JC013825

Stewart, A. L., Klocker, A., and Menemenlis, D. (2018). Circum-antarctic shoreward heat transport derived from an eddy-and tide-resolving simulation. Geophys. Res. Lett. 45, 834-845. doi: 10.1002/2017GL0 75677

Stopa, J. E., Sutherland, P., and Ardhuin, F. (2018). Strong and highly variable push of ocean waves on southern ocean sea ice. Proc. Nat. Acad. Sci. U.S.A. 115, 5861-5865. doi: 10.1073/pnas.1802011115

The SKIM Team (2017). Sea Surface Kinematics Multiscale Monitoring, Full Proposal for ESA EE9. Technical Report, Laboratoire d'Océanographie Physique et Spatiale, Brest. Prepared for European Space Agency, 192.

Torres, H. S., Klein, P., Menemenlis, D., Qiu, B., Su, Z., Wang, J., et al. (2018). Partitioning ocean motions into balanced motions and internal gravity waves: a modeling study in anticipation of future space missions. J. Geophys. Res. 123, 8084-8105. doi: 10.1029/2018JC014438

van Sebille, E., Griffies, S. M., Abernathey, R., Adams, T. P., Berloff, P. S., Biastoch, A., et al. (2018). Lagrangian ocean analysis: fundamentals and practices. Ocean Modell. 121, 49-75. doi: 10.1016/j.ocemod.2017.11.008

Yurovsky, Y. Y., Kudryavtsev, V. N., Chapron, B., and Grodsky, S. A. (2018). Modulation of ka-band doppler radar signals backscattered from the sea surface. IEEE Trans. Geosci. Remote Sens. 56, 2931-2948. doi: 10.1109/TGRS.2017.2787459
Yurovsky, Y. Y., Kudryavtsev, V. N., Grodsky, S. A., and Chapron, B. (2017). Ka-band dual copolarized empirical model for the sea surface radar cross section. IEEE Trans. Geosci. Remote Sens. 55, 1629-1647. doi: 10.1109/TGRS.2016.2628640

Conflict of Interest Statement: HJ and GE were employed by company NORUT Teknologi AS.

The remaining authors declare that the research was conducted in the absence of any commercial or financial relationships that could be construed as a potential conflict of interest.

The reviewer SG declared a past co-authorship with one of the authors BC to the handling editor.

Copyright (C) 2019 Ardhuin, Brandt, Gaultier, Donlon, Battaglia, Boy, Casal, Chapron, Collard, Cravatte, Delouis, De Witte, Dibarboure, Engen, Johnsen, Lique, Lopez-Dekker, Maes, Martin, Marié, Menemenlis, Nouguier, Peureux, Rampal, Ressler, Rio, Rommen, Shutler, Suess, Tsamados, Ubelmann, van Sebille, van den Oever and Stammer. This is an open-access article distributed under the terms of the Creative Commons Attribution License (CC BY). The use, distribution or reproduction in other forums is permitted, provided the original author(s) and the copyright owner(s) are credited and that the original publication in this journal is cited, in accordance with accepted academic practice. No use, distribution or reproduction is permitted which does not comply with these terms. 